\title{
A NEW TECHNIQUE OF TALECTOMY FOR SEVERE FRACTURE-DISLOCATION OF THE TALUS
}

\author{
ISGE GÜNAL, SELÇUK ATILLA, ŞÜKRÜ ARAÇ, YUSUF GÜRSOY, HAKAN KARAGÖZLU
}

From the State Hospital, Izmir, Turkey

We report a new technique of talectomy for patients with Hawkins group III fracture-dislocation of the talus. Talectomy is performed through a medial incision, the foot is displaced anteriorly, and the fractured or osteotomised medial malleolus is moved laterally and fixed to the tibia with a malleolar screw. Full weightbearing is allowed after six weeks.

In four patients at $\mathbf{3 6}$ to $\mathbf{5 7}$ months after operation the results were excellent in three and good in one, with no pain or early evidence of degenerative arthritis in the remaining joints of the foot.

J Bone Joint Surg [Br] 1993;75-B :69-71.

Received 28 October 1991; Accepted 11 June 1992

Talectomy is sometimes indicated for severe foot deformity in patients with myelomeningocele, arthrogryposis multiplex congenita or postpoliomyelitic paralysis. It has also been used to treat severe fracture-dislocation of the neck of the talus (Hawkins group III) when the body of the talus is completely avascular (Coltart 1952; Detenbeck and Kelly 1969; Hawkins 1970; Morris, Hand and Dunn 1971; Canale and Kelly 1978; Cooper and Capello 1985). Complications include pain, a limp, leg shortening and a decreased range of movement, but the alternative of tibiotalar fusion (Blair 1943) has not given encouraging results (Morris et al 1971; Canale and Kelly 1978).

We describe a new technique for talectomy (developed by IG) in which the calcaneum is displaced, not

I. Günal, MD, Assistant Professor

Department of Orthopaedics, School of Medicine, University of Anadolu, Eskişehir, Turkey.

S. Atilla, MD, Professor

S. Araç, MD, Associate Professor

Y. Gürsoy, MD, Resident

H. Karagözlu, MD, Resident

Department of Orthopaedics, State Hospital, Izmir, Turkey.

Correspondence should be sent to Dr I. Günal at Öğretmenler Mah, 2 Sokak No: 10, 10700 Burhaniye, Turkey.

(C)1993 British Editorial Society of Bone and Joint Surgery $0301-620 \mathrm{X} / 93 / 1489 \$ 2.00$ backwards as in the classical method, but anteriorly to make contact between the distal articular surface of the tibia and the posterior articular facet of the calcaneum. The medial malleolus is displaced laterally and screwed into position to narrow and stabilise the new pseudarthrosis.

\section{PATIENTS AND METHODS}

From January 1987 to September 1988, we treated four patients with fractures of the neck of the talus and complete dislocation of the body fragment (Hawkins group III) by talectomy using the new technique. There were three men and one woman; their ages ranged from 19 to 41 years. Follow-up was from 36 to 57 months (Table I). Three patients had closed fracture-dislocations and two of them had associated fractures of the medial malleolus. One patient was diabetic (case 2).

Operative technique. The operation is performed under general anaesthesia, with the patient supine, and with the use of a tourniquet. A curved medial incision starts $5 \mathrm{~cm}$ proximal and $2.5 \mathrm{~cm}$ posterior to the medial malleolus, curving forwards across the centre of the malleolus and then back and down for $4 \mathrm{~cm}$ towards the heel (Fig. 1). The medial malleolus is exposed by reflecting its periosteum, but preserving the deltoid ligament. The

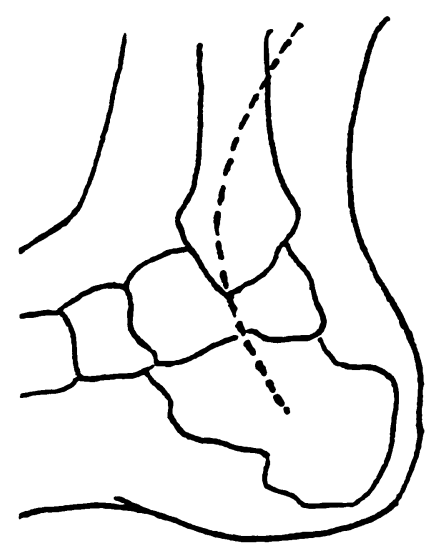

Fig. 1

Diagram of the skin incision for talectomy. 
Table I. Clinical details of four patients who had talectomy after a severe fracture-dislocation

\begin{tabular}{|c|c|c|c|c|c|c|c|c|c|}
\hline \multirow[b]{2}{*}{ Case } & \multirow[b]{2}{*}{ Sex } & \multirow{2}{*}{$\begin{array}{l}\text { Age } \\
(\mathbf{y r})\end{array}$} & \multirow{2}{*}{$\begin{array}{l}\text { Mechanism } \\
\text { of injury }\end{array}$} & \multirow{2}{*}{$\begin{array}{l}\text { Type of } \\
\text { injury }\end{array}$} & \multirow{2}{*}{$\begin{array}{l}\text { Fracture } \\
\text { of medial } \\
\text { malleolus }\end{array}$} & \multirow{2}{*}{$\begin{array}{l}\text { Follow-up } \\
\text { (mth) }\end{array}$} & \multicolumn{2}{|c|}{$\begin{array}{l}\text { Total range of } \\
\text { foot movement }\end{array}$} & \multirow[b]{2}{*}{ Result } \\
\hline & & & & & & & DP* & IE $\dagger$ & \\
\hline 1 & $\mathbf{M}$ & 19 & $\begin{array}{l}\text { Fall from } \\
\text { a height }\end{array}$ & $\begin{array}{l}\text { Closed } \\
\text { Hawkins III }\end{array}$ & Yes & 57 & 60 & 30 & Excellent \\
\hline 2 & $\mathbf{M}$ & 40 & $\begin{array}{l}\text { Road-traffic } \\
\text { accident }\end{array}$ & $\begin{array}{l}\text { Open } \\
\text { Hawkins III }\end{array}$ & No & 45 & 50 & 25 & Good \\
\hline 3 & $\mathrm{~F}$ & 35 & $\begin{array}{l}\text { Road-traffic } \\
\text { accident }\end{array}$ & $\begin{array}{l}\text { Closed } \\
\text { Hawkins III }\end{array}$ & No & 36 & 55 & 20 & Excellent \\
\hline 4 & $\mathbf{M}$ & 41 & $\begin{array}{l}\text { Fall from } \\
\text { a height }\end{array}$ & $\begin{array}{l}\text { Closed } \\
\text { Hawkins III }\end{array}$ & Yes & 43 & 60 & 30 & Excellent \\
\hline
\end{tabular}

* dorsiflexion-plantar flexion in degrees

$\dagger$ inversion-eversion in degrees

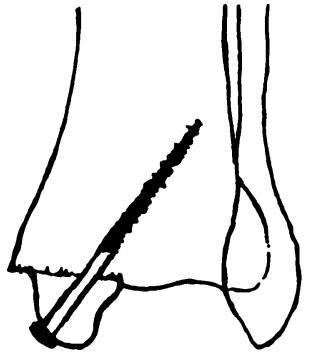

Fig. 2

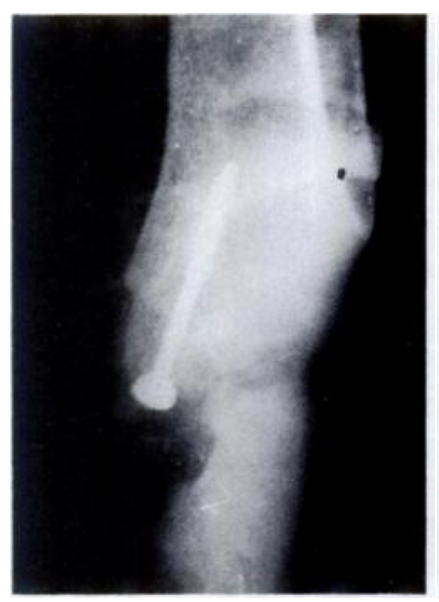

Fig. 3

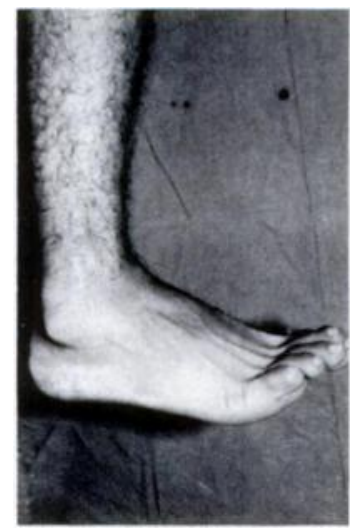

Fig. 5

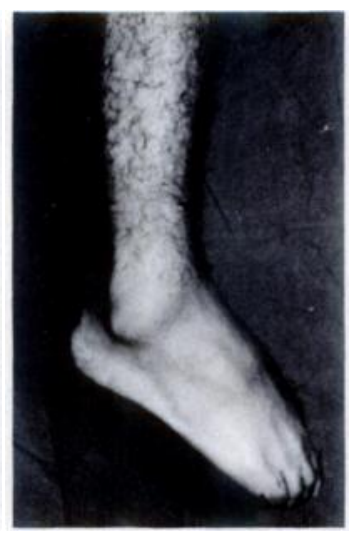

Fig. 6

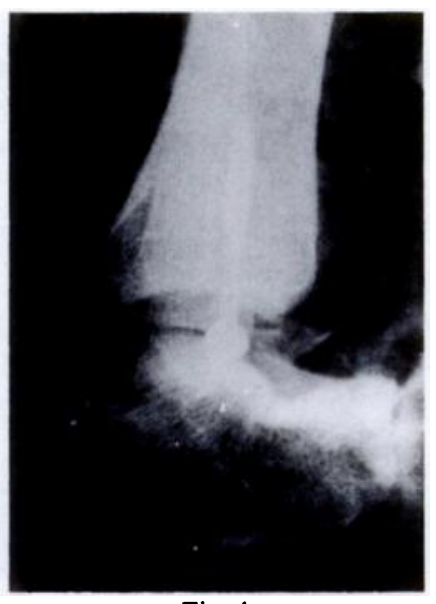

Fig. 4

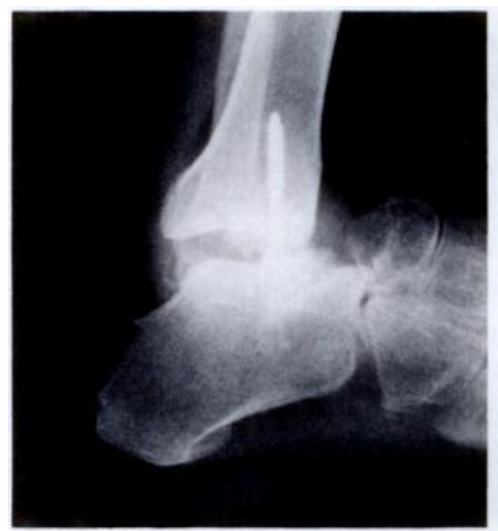

Fig. 7

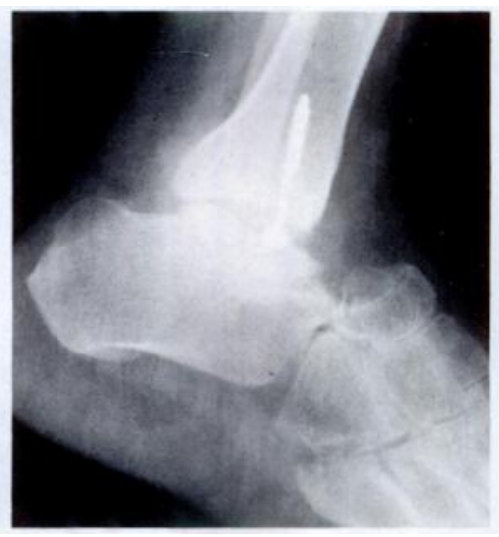

Fig. 8

Photographs and radiographs (case 1) showing the anterior displacement of the foot and the range of flexion-extension movement.

flexor sheath is opened, and the tendon of flexor hallucis longus is retracted posteriorly with the neurovascular bundle. The tibialis posterior and flexor digitorum longus tendons are retracted anteriorly. If the medial malleolus is not already fractured, it is osteotomised transversely at the level of the tibiotalar joint line and turned down on the deltoid ligament. The whole of the talus is then meticulously resected at the tibiotalar, subtalar and
Figure 2 - Diagram of the osteotomy, displacement and fixation of the medial malleolus. Figures 3 and 4 - Postoperative radiographs showing the displaced malleolus and the new pseudarthrosis. talonavicular joints, dividing ligaments cleanly, leaving no bony fragments.

When talectomy is complete the foot is displaced anteriorly so that the distal tibial articular surface contacts the posterior facet of the calcaneum. The medial part of the articular cartilage on the distal tibia is resected so that the fractured or osteotomised medial malleolus can be displaced laterally to create a new joint, medially, 
with the sulcus calcanei. The displaced malleolus is then fixed with a screw (Figs 2 to 4 ).

After the operation the foot is held in a neutral position, and placed in a below-knee plaster. After three weeks, the plaster is removed and partial weight-bearing is allowed. Full weight-bearing is usually possible after a further three weeks.

\section{RESULTS}

Following the criteria of Morris et al (1971), three of our four patients had excellent results, being able to return to full activity with completely asymptomatic feet and ankles (Table I). One patient had a good result, with occasional discomfort causing no restriction of activities. No patient had a limit to normal activities or required analgesia. One patient (case 2) had required splitthickness skin grafting for an area of necrosis of the wound, but had a good result.

On examination at 36 to 57 months, none of our patients had a detectable limp and they had all returned to their former occupations. There was an average of $1 \mathrm{~cm}$ shortening, but no patient required a heel-lift. At latest follow-up, no patient had any evidence of degenerative arthritis of the foot joints. The range of dorsiflexion and plantar flexion of the forefoot was from $60^{\circ}$ to $70^{\circ}$; about $50 \%$ of this was movement at the new tibiocalcaneal pseudarthrosis (Figs 5 to 8). Inversioneversion movements were about $70 \%$ of normal.

\section{DISCUSSION}

The precarious blood supply of the talus (Haliburton et al 1958; Mulfinger and Trueta 1970) makes avascular necrosis almost inevitable in severely displaced (Hawkins group III) fracture-dislocations. Talectomy, with or without fusion, or Blair's tibiotalar fusion are therefore recommended (Blair 1943; Hawkins 1970; Morris et al 1971: Canale and Kelly 1978) although both procedures are known to have disadvantages. Simple talectomy may produce shortening of the leg with a limp, a reduced range of movement and osteoarthritis of the remaining joints. Blair's fusion between the remaining talar neck and the tibia, may also result in a decreased range of movement and osteoarthritis, with a risk of tibiocalcaneal collapse and shortening (Hawkins 1970; Morris et al 1971 ; Canale and Kelly 1978).

In the classical technique of talectomy, the foot is displaced posteriorly. Holmdahl (1956) thought that the result was likely to be poor if this was not achieved. As mentioned by Menelaus (1971), however, posterior displacement of the foot often produces a poor fit between the upper surface of the calcaneum and the ankle mortise: the lateral malleolus tends to abut against the lateral surface of the calcaneus. Our new technique, of displacing the medial malleolus laterally, obtained an excellent fit between the distal tibial articular surface and the posterior articular facet of the calcaneum. This good contact between the surfaces allows relatively rapid mobilisation and early weight-bearing. In our cases full weight-bearing became possible at six weeks, as compared with the much longer time sometimes required after talectomy or Blair's fusion (Morris et al 1971; Cooper and Capello 1985).

The anterior position of the foot also allows a wider range of movement, because posterior displacement places the tibia near the navicular which acts as a dorsiflexion stop. Hawkins (1970) reported considerable loss of ankle and subtalar movement after talectomy; we obtained an adequate functional range of dorsiflexion and plantar flexion.

Hsu, Jaffray and Leong (1984) reported that $47 \%$ of talectomies develop spontaneous fusion, and that this increases the risk of early arthritic changes in the other joints of the foot. Much the same risk applies to Blair's fusion. We found no degenerative changes in our patients after 3 to 4.6 years.

The displacement, after its fracture or osteotomy, of the medial malleolus, is an important part of our technique and also allows better visualisation of the operative field.

The main theoretical advantage of Blair's fusion is that it prevents loss of height, but the minor leg shortening in our patients produced no detectable limp and did not necessitate the use of heel-lifts.

Conclusion. Displacement of the foot anteriorly and of the medial malleolus laterally is an effective technique of talectomy for patients with Hawkins group III fracturedislocation of the talus.

No benefits in any form have been received or will be received from a commercial party related directly or indirectly to the subject of this article.

\section{REFERENCES}

Blair HC. Comminuted fractures and fracture dislocations of the body of astralagus: operative treatment. Am J Surg 1943; 59:37-43.

Canale ST, Kelly FB. Fractures of the neck of the talus: long-term evaluation of seventy-one cases. $J$ Bone Joint Surg [Am] 1978; 60A :143-56.

Coltart WD. “A viators astralagus”. J Bone Joint Surg [Br] 1952; 34B:545-66.

Cooper RR, Capello W. Talectomy: a long-term follow-up evaluation. Clin Orthop 1985; $201: 32-5$.

Detenbeck LC, Kelly PJ. Total dislocation of the talus. J Bone Joint Surg [Am] 1969; 51-A :283-8.

Haliburton RA, Sullivan CR, Kelly PJ, Peterson LFA. The extra-osseous and intra-osseous blood supply of the talus. J Bone Joint Surg [Am] $1958 ; 40-A: 1115-20$

Hawkins LG. Fractures of the neck of the talus. J Bone Joint Surg [Am] 1970; 52-A:991-1002.

Holmdahl HC. Astragalectomy as a stabilising operation for foot paralysis following poliomyelitis: results of a follow-up investigation of 153 cases. Acta Orthop Scand 1956;25:207-27.

Hsu LCS, Jafiray D, Leong JCY. Talectomy for club foot in arthrogryposis. J Bone Joint Surg [Br] 1984; 66-B :694-6.

Menelaus MB. Talectomy for equinovarus deformity in arthrogryposis and spina bifida. J Bone Joint Surg [Br] 1971 ; 53-B:468-73.

Morris HD, Hand WL, Dunn AW. The modified Blair fusion for fractures of the talus. J Bone Joint Surg [ Am] 1971 ; 53-A :1289-97.

Mulfinger GL, Trueta J. The blood supply of the talus. J Bone Joint Surg [Br] 1970; 52-B:160-7. 